\title{
Short communication: Estimates of heritabilities and genetic correlations among milk fatty acid unsaturation indices in Canadian Holsteins
}

\author{
G. Bilal, R. I. Cue, A. F. Mustafa, and J. F. Hayes ${ }^{1}$ \\ Department of Animal Science, McGill University, Macdonald Campus, Ste-Anne-de-Bellevue, Quebec, Canada, H9X 3V9
}

\begin{abstract}
The objectives of the present study were to estimate genetic parameters of milk fatty acid unsaturation indices in Canadian Holsteins. Data were available on milk fatty acid composition of 2,573 Canadian Holstein cows from 46 commercial herds enrolled in the Québec Dairy Production Centre of Expertise, Valacta (SainteAnne-de-Bellevue, Quebec, Canada). Individual fatty acid percentages $(\mathrm{g} / 100 \mathrm{~g}$ of total fatty acids) were determined for each milk sample by gas chromatography. The unsaturation indices were calculated as the ratio of an unsaturated fatty acid to the sum of that unsaturated fatty acid and its corresponding substrate fatty acid, multiplied by 100. A mixed linear model was fitted under REML for the statistical analysis of milk fatty acid unsaturation indices. The statistical model included the fixed effects of parity, age at calving, and stage of lactation, each nested within parity, and the random effects of herd-year-season of calving, animal, and residual. Estimates of heritabilities for the C14, C16, C18, conjugated linoleic acid, and total unsaturation indices were $0.48,0.25,0.29,0.14$, and 0.19 , respectively. Phenotypic and genetic correlation estimates among unsaturation indices were all positive and ranged from 0.20 to 0.65 and 0.23 to 0.81 , respectively. The estimates of heritabilities and genetic correlations for milk fatty acid unsaturation indices suggest that genetic variation exists among cows in milk fatty acid unsaturation, and the proportions of desirable unsaturated fatty acids from a human health point of view may be increased in bovine milk through genetic selection.
\end{abstract}

Key words: milk fatty acid unsaturation index, genetic parameter, dairy cattle

\section{Short Communication}

Saturated FA are abundant in bovine milk fat. Some saturated FA have been shown to negatively affect hu-

Received May 2, 2012.

Accepted August 13, 2012.

${ }^{1}$ Corresponding author: john.f.hayes@mcgill.ca man health, whereas MUFA and PUFA are considered good from a human health point of view (Haug et al., 2007; Sun et al., 2007). Therefore, in the dairy industry, interest is growing in increasing the proportions of unsaturated FA and decreasing the proportions of SFA in bovine milk. Diet and genetic selection are the 2 major tools that can be used to achieve the required goal of a healthier FA profile in bovine milk. Recent studies have suggested that genetic variation exists among cows in milk FA content, and genetic selection can be used to alter the FA composition of bovine milk in a desirable direction (Bobe et al., 2008; Stoop et al., 2008).

Stearoyl-CoA desaturase (SCD) is an important enzyme that plays a central role in the synthesis of MUFA and is the most important isomer of conjugated linoleic acid (CLA; i.e., C18:2 cis-9, trans-11) in cattle. In the bovine mammary gland, SCD inserts a cis-double bond at the $\Delta^{9}$ position in a wide range of $\mathrm{FA}$ (Ntambi and Miyazaki, 2004) and it is therefore also called the $\Delta^{9}$ desaturase enzyme. Conjugated linoleic acid is a natural anticarcinogen present in the milk fat of ruminants (Parodi, 1999). Conjugated linoleic acid is produced as an intermediate during the biohydrogenation of linoleic acid (Kepler and Tove, 1967). However, recent nutritional studies have demonstrated that most of the CLA in the milk fat of lactating dairy cows is synthesized endogenously from C18:1 trans-11 (or trans-vaccenic acid, another intermediate of ruminal biohydrogenation) by the enzymatic activity of SCD (Griinari et al., 2000; Corl et al., 2001). Kay et al. (2004) reported that $91 \%$ of the CLA in milk fat of pasture-fed cows was produced endogenously. Increasing the proportions of CLA and oleic acid in particular, and C14:1 cis-9 and C16:1 cis-9 in general, could substantially improve the human health aspects of milk and dairy products. To study the enzymatic activity of SCD in the mammary gland of dairy cows, unsaturation indices are often used as a proxy (Kelsey et al., 2003). An unsaturation index is calculated as the proportion of the concentration of unsaturated FA (product) to the sum of that unsaturated FA and the corresponding SFA (substrate) (Kelsey et al., 2003; Schennink et al., 2008).

A few studies have estimated genetic parameters of the unsaturation indices in dairy cows and have re- 
ported that genetic variation exists among cows in SCD enzyme activity, and that this variation may be used to increase the proportions of CLA and MUFA in bovine milk (Schennink et al., 2008; Soyeurt et al., 2008; Mele et al., 2009; Garnsworthy et al., 2010). No study has reported on the genetic parameters of unsaturation indices in Canadian Holsteins. Therefore, the objective of the present study was to estimate heritabilities of, and genetic and phenotypic correlations among, milk FA unsaturation indices in Canadian Holsteins.

Milk FA data on 2,573 Canadian Holstein cows from 46 commercial herds enrolled in Valacta (SainteAnne-de-Bellevue, QC, Canada), which were sampled between February and June 2010, were used for the present study. Parity of cows ranged from 1 to 8 . Cows were sampled between 3 and 450 DIM. Fatty acid composition of each milk fat sample was determined by gas chromatography. The milk FA unsaturation indices were calculated as ratio of the product (unsaturated FA) to the product plus substrate (corresponding SFA), multiplied by 100 (Schennink et al., 2008) as follows:

$$
\begin{aligned}
& \text { C14 index }=[\mathrm{C} 14: 1 \text { cis-9/ } \\
& (\mathrm{C} 14: 0+\mathrm{C} 14: 1 \text { cis-9)] } \times 100, \\
& \mathrm{C} 16 \text { index }=[\mathrm{C} 16: 1 \text { cis-9/ } \\
& (\mathrm{C} 16: 0+\mathrm{C} 16: 1 \text { cis-9)] } \times 100, \\
& \mathrm{C} 18 \text { index }=[\mathrm{C} 18: 1 \text { cis-9 } / \\
& (\mathrm{C} 18: 0+\mathrm{C} 18: 1 \text { cis-9)] } \times 100, \\
& \text { CLA index }=[\mathrm{C} 18: 2 \text { cis- } 9, \text { trans-11 }] \\
& \text { (C18:1 trans }-11+\mathrm{C} 18: 2 \text { cis-9, trans }-11)] \times 100, \\
& \text { total index }=[(\mathrm{C} 14: 1 \text { cis-9 }+\mathrm{C} 16: 1 \text { cis }-9 \\
& +\mathrm{C} 18: 1 \text { cis-9 + C18:2 cis-9, trans-11)/(C14:0 } \\
& \text { + C14:1 cis-9 + C16:0 + C16:1 cis-9 + C18:0 } \\
& +\mathrm{C} 18: 1 \text { cis- } 9+\mathrm{C} 18: 1 \text { trans-11 } \\
& +\mathrm{C} 18: 2 \text { cis-9, trans-11)] } \times 100 \text {. }
\end{aligned}
$$

The following linear mixed model was used for the estimation of genetic parameters in the Wombat program (Meyer, 2007):

$$
\begin{aligned}
Y_{i j k l m}= & +P_{i}+A_{j(i)}+S_{k(i)}+\mathrm{HYS}_{l} \\
& +\operatorname{Animal}_{m}+E_{i j k l m},
\end{aligned}
$$

where $Y_{i j k l m}$ is a measurement of the unsaturation index from a milk sample of the $m$ th cow in the lth herd-year- season class, $k$ th stage of lactation class in the $i$ th parity, and $j$ th age at calving class in the $i$ th parity; $\mu$ is the overall population mean; $P_{i}$ is the fixed effect of the ith parity ( 3 levels: parity 1,2 , and $\geq 3$ ); $A_{j(i)}$ is the fixed effect of the $j$ th age at calving nested within the $i$ th parity (57 levels); $S_{k(i)}$ is the fixed effect of the $k$ th stage of lactation nested within the ith parity (107 levels); $\mathrm{HYS}_{l}$ refers to the random effect of the $l$ th herdyear-season of calving (115 levels), assumed to be distributed as $N\left(0, \mathbf{I} \sigma_{\text {hys }}^{2}\right)$, where $\mathbf{I}$ is the identity matrix; Animal $_{m}$ is the random additive genetic effect of the $m$ th animal, assumed to be distributed as $N\left(0, \mathbf{A} \sigma_{a}^{2}\right)$, where $\mathbf{A}$ is the additive genetic relationship matrix among animals; and $E_{i j k l m}$ is the random residual associated with each record, assumed to be distributed as $N\left(0, \mathbf{I} \sigma_{e}^{2}\right)$. The parity $\times$ stage of lactation (interaction) effect was statistically significant $(P<0.05)$ for most unsaturation indices; therefore, stage of lactation was fitted as nested within parity in the model of analysis. Likewise, the herd $\times$ year-season of calving (interaction) effect was significant for all unsaturation indices; therefore, a random effect of herd-year-season of calving (HYS) was included in the model of analysis.

Three parity classes were defined: 1 for first-parity cows, 2 for second-parity cows, and 3 for cows in parity 3 or more. Age at calving classes were defined as follows: 21 to $22,23,24, \ldots, 32$, and 33 to 37 mo of age for first-parity cows; 33 to $34,35,36, \ldots, 49$, and 50 to 52 mo of age for second-parity cows; 45 to $46,47,48, \ldots$, 69,70 to 79,80 to 89,90 to 99 , and $\geq 100$ mo of age for cows in parity 3 or more. Stage of lactation classes were formed as follows: 3 to 10, 11 to 20,21 to $30, \ldots, 320$ to 330,331 to 350,351 to 370 , and 371 to 450 DIM. Four year-season of calving classes were created (September 2008 to February 2009, March 2009 to August 2009, September 2009 to February 2010, March 2010 to June 2010). Each HYS class was required to have 5 or more observations.

The relationships among animals were accounted for on both the male and female side. The Holstein pedigree file provided by the Canadian Dairy Network (Guelph, ON, Canada) was used to extract the pedigree of cows, with data traced back 5 generations. The extracted pedigree file contained 15,732 animals. This pedigree file was pruned to remove all noninformative animals from a genetic standpoint. This removed 2,630 animals. The final pedigree file consisted of 13,102 animals. A total of 580 sires and 2,177 dams had progeny with phenotypes in the data. The data for all unsaturation indices were normally distributed. Estimates of heritabilities (defined as the proportion of additive genetic variance to phenotypic variance) of and genetic and 
phenotypic correlations among milk FA unsaturation indices were obtained by fitting the above model as a multivariate ( 5 traits) animal model under REML by using Wombat software (Meyer, 2007).

Basic statistics of the unsaturation indices are given in Table 1. The C18 index had the highest mean value (66.95\%), followed by the CLA index (26.35\%). Medium-chain FA unsaturation indices C14 (7.36\%) and C16 (4.96\%) had low mean values. The results suggest that long-chain FA (C18:0 and higher) are unsaturated to a greater extent than medium-chain FA (C14:0 and C16:0). These results are in agreement with earlier studies on dairy cows (Kelsey et al., 2003; Schennink et al., 2008). Schennink et al. (2008) suggested that the difference between unsaturation indices of long-chain and medium-chain FA may be explained by the difference in the synthesis of their substrate FA. Almost all the $\mathrm{C} 14: 0$ and about half the C16:0 FA are synthesized de novo in the mammary gland, whereas almost all the C18 and longer chain FA are of dietary origin. The coefficients of variation for the C14, C16, and CLA indices ranged from 22.23 to $28.63 \%$, whereas the $\mathrm{C} 18$ index showed the lowest coefficient of variation (6.60\%). The coefficients of variation for the unsaturation indices are comparable with earlier literature estimates (Schennink et al., 2008; Mele et al. 2009). The coefficient of variation for the CLA index was highest (28.63\%) among all the FA unsaturation indices, suggesting a substantial amount of variation among cows in the CLA index. Kelsey et al. (2003) observed approximately a 3-fold range in both milk fat content of CLA (0.24 to 0.72\%) and the CLA unsaturation index (0.15 to $0.37 \%$ ) among US Holsteins fed a single diet in a single herd.

The estimates of phenotypic variance and variance of each random effect in the model of analysis for milk FA unsaturation indices are reported in Table 1. The proportion of variance for HYS for the C14 index was low (10.5\%), whereas the proportion of variance attributable to HYS was high for the $\mathrm{C} 16, \mathrm{C} 18$, and CLA indices and ranged from 18.9 to $22.3 \%$. The proportion of variance for HYS was highest for the total index $(26.3 \%)$. The proportions of HYS variance for individual unsaturation indices reported in the pres- ent study are higher than those reported by Schennink et al. (2008) for the proportion of herd variance (6 to $9 \%$ ), whereas the proportion of HYS variance for the total unsaturation index was very similar $(26 \%)$ to the proportion of herd variance reported by Schennink et al. (2008). As pointed out by Schennink et al. (2008), C16:0 and C18:1 cis-9 are the most abundant FA in bovine milk, and the total unsaturation index is mainly an indicator of the ratio of C18:1 cis-9 to C16:0.

The estimates of heritabilities and genetic and phenotypic correlations for milk FA unsaturation indices are reported in Table 2. Heritability estimates of the unsaturation indices ranged from 0.14 to 0.48 . The $\mathrm{C} 14$ index had the highest heritability estimate $(0.48)$, and the CLA index had the lowest heritability estimate (0.14). Heritability estimates of the $\mathrm{C} 16$ and $\mathrm{C} 18$ indices were 0.25 and 0.29 , respectively, and the total index had a heritability estimate of 0.19. Schennink et al. (2008) reported a similar intraherd heritability (0.45) estimate for the $\mathrm{C} 14$ index and higher intraherd heritability estimates for the C16 (0.46), C18 (0.33), CLA (0.23), and total indices (0.30) in a study on 1,933 Holstein cows. Their study was based on first-lactation cows sampled between 63 and 282 DIM, resulting in a less heterogeneous environment, and they defined heritability as intraherd heritability (ratio of additive genetic variance to the sum of additive genetic and residual variance) in which herd variance was not included. Garnsworthy et al. (2010), in a study on 2,408 Holstein-Friesian cows in the United Kingdom using a sire model analysis, reported lower estimates of heritability for the C14 (0.38), C16 (0.05), and C18 (0.19) unsaturation indices but higher heritability for the CLA index (0.21) compared with the current estimates. Mele et al. (2009) reported lower heritability estimates than current estimates for the C14 (0.27), C16 (0.12), C18 (0.13), and total unsaturation (0.15) indices in a study on 990 Italian Holstein cows. However, they reported a very similar heritability estimate for the CLA index $(0.15)$. The heritability estimates of unsaturation indices reported by Royal and Garnsworthy (2005) were lower than the current estimates for the C14 (0.30) and C18 (0.19) indices and were very low for the C16 (0.01)

Table 1. Means, CV, and estimates of phenotypic variance $\left(\sigma_{p}^{2}\right)$, herd-year-season of calving (HYS) variance $\left(\sigma_{\text {hys }}^{2}\right)$, additive genetic variance $\left(\sigma_{a}^{2}\right)$, and residual variance $\left(\sigma_{r}^{2}\right)$ of FA unsaturation indices based on milk samples from 2,573 Canadian Holstein cows

\begin{tabular}{lcrrrrr}
\hline Item & Mean $(\%)$ & $\mathrm{CV}(\%)$ & \multicolumn{1}{c}{$\sigma_{p}^{2} \pm \mathrm{SE}$} & \multicolumn{1}{c}{$\sigma_{\text {hys }}^{2} \pm \mathrm{SE}$} & $\sigma_{a}^{2} \pm \mathrm{SE}$ & \multicolumn{1}{c}{$\sigma_{r}^{2} \pm \mathrm{SE}$} \\
\hline C14 index & 7.36 & 25.38 & $2.89 \pm 0.11$ & $0.30 \pm 0.06$ & $1.37 \pm 0.20$ & $1.22 \pm 0.14$ \\
C16 index & 4.96 & 22.23 & $0.99 \pm 0.04$ & $0.19 \pm 0.03$ & $0.24 \pm 0.05$ & $0.56 \pm 0.04$ \\
C18 index & 66.95 & 6.60 & $18.72 \pm 0.79$ & $3.58 \pm 0.61$ & $5.39 \pm 1.09$ & $9.75 \pm 0.84$ \\
CLA index & 26.35 & 28.63 & $53.66 \pm 2.34$ & $11.94 \pm 2.00$ & $7.66 \pm 2.22$ & $34.06 \pm 1.97$ \\
Total index & 28.91 & 15.21 & $13.54 \pm 0.65$ & $3.56 \pm 0.57$ & $2.60 \pm 0.59$ & $7.38 \pm 0.50$ \\
\hline
\end{tabular}


Table 2. Estimates of heritabilities (along diagonals) of and genetic (below diagonals) and phenotypic (above diagonals) correlations ( \pm SE) among milk fatty acid unsaturation indices based on milk samples from 2,573 Canadian Holsteins

\begin{tabular}{llllll}
\hline Item & C14 index & C16 index & C18 index & CLA index & Total index \\
\hline C14 index & $0.48( \pm 0.06)$ & $0.52( \pm 0.02)$ & $0.58( \pm 0.02)$ & $0.35( \pm 0.02)$ & $0.26( \pm 0.03)$ \\
C16 index & $0.38( \pm 0.10)$ & $0.25( \pm 0.05)$ & $0.63( \pm 0.02)$ & $0.29( \pm 0.03)$ & $0.65( \pm 0.02)$ \\
C18 index & $0.35( \pm 0.10)$ & $0.54( \pm 0.10)$ & $0.29( \pm 0.05)$ & $0.56( \pm 0.02)$ & $0.51( \pm 0.03)$ \\
CLA index & $0.23( \pm 0.14)$ & $0.28( \pm 0.16)$ & $0.81( \pm 0.08)$ & $0.14( \pm 0.04)$ & $0.20( \pm 0.03)$ \\
Total index & $0.30( \pm 0.12)$ & $0.40( \pm 0.12)$ & $0.78( \pm 0.08)$ & $0.40( \pm 0.16)$ & $0.19( \pm 0.04)$ \\
\hline
\end{tabular}

and total (0.02) indices in a study using a sire model with 1,520 Holstein-Friesian cows. Soyeurt et al. (2008) reported lower heritability estimates for C14 (0.20) and C16 (0.20) indices and a very low heritability estimate for the C16 index (0.03) based on data on repeated milk samples from a total of 1,918 cows sampled from 7 different breeds in Belgium. They used midinfrared spectrometry to predict FA composition of milk as compared with gas chromatography analysis used in the present and other studies. Overall, the heritability estimates reported in the present study suggest that genetic variation in milk FA unsaturation exists among dairy cows, and this variation could be exploited in a selection program to increase the proportions of unsaturated FA and to decrease the proportions of SFA in bovine milk.

The estimates of phenotypic correlations among all the unsaturation indices were positive and ranged from 0.20 to 0.65 . The estimates of genetic correlations among all the unsaturation indices were also positive and ranged from 0.23 to 0 . 81. In particular, the $\mathrm{C} 18$ index showed strong positive genetic correlations with the C16 (0.54), CLA (0.81), and total (0.78) indices. In general, the genetic and phenotypic correlation estimates among the unsaturation indices reported in the present study are comparable with those reported in previous studies (Schennink et al., 2008; Soyeurt et al., 2008; Mele et al., 2009). The present study did not estimate correlations between unsaturation indices and production traits. Previously, Schennink et al. (2008) and Mele et al. (2009) reported positive genetic correlations of fat percentage with $\mathrm{C} 14$ and $\mathrm{C} 16$ indices and negative genetic correlations of fat percentage with C18 and CLA indices. According to Soyeurt et al. (2008), C14, C16, and C18 indices all showed close to zero genetic correlations with milk yield and negative genetic correlations with protein and fat percentages.

Genetic selection on unsaturation indices could be advantageous to improve milk fat quality because of their moderate to high heritabilities (Schennink et al., 2008; Soyeurt et al., 2008; Mele et al., 2009). However, direct selection for ratio values may cause a stronger selection pressure on the denominator trait than on the numerator trait (Essl, 1989; Campo and Rodríguez,
1990). Gunsett (1984), in a simulation study, reported that direct selection on ratio traits could result in disproportionate selection pressure being exerted on the component traits, and they concluded that a linear index could more efficiently improve the ratios of measured traits than could direct selection on the ratios of traits. In any case, the current study and other studies on unsaturation indices provide evidence of genetic variation in the milk FA unsaturation activity among dairy cows, and methods of selection to exploit this variation should be encouraged so as to improve the nutritional quality of milk fat.

In conclusion, all unsaturation indices showed moderate to high heritability estimates, indicating that additive genetic variation exists in the milk FA unsaturation indices among dairy cows, and genetic selection could be devised to increase the proportions of desirable unsaturated FA and decrease the proportions of undesirable SFA in bovine milk. Genetic and phenotypic correlation estimates among unsaturation indices were all positive, suggesting that all the C14:1 cis-9, C16:1 cis-9, C18:1 cis-9, and cis-9, trans-11 CLA could be increased simultaneously by selection for increased milk FA unsaturation activity among dairy cows.

\section{ACKNOWLEDGMENTS}

The authors acknowledge the DairyGen Council of the Canadian Dairy Network (Guelph, ON, Canada) and Natural Sciences and Engineering Research Council of Canada (Ottawa, ON, Canada) for funding this project. The authors also acknowledge the Higher Education Commission (Islamabad, Pakistan) and the Arid Agriculture University (Rawalpindi, Pakistan) for awarding the $\mathrm{PhD}$ scholarship to G. Bilal. The authors thank Robert Moore and Brian Corrigan of Valacta (Sainte-Anne-de-Bellevue, QC, Canada) for their assistance in organizing collection of milk samples. The authors thank K. Meyer for making the WOMBAT software available.

\section{REFERENCES}

Bobe, G., J. A. Minick Bormann, G. L. Lindberg, A. E. Freeman, and D. C. Beitz. 2008. Short communication: Estimates of genetic 
variation of milk fatty acids in US Holstein cows. J. Dairy Sci. 91:1209-1213.

Campo, J. L., and M. Rodríguez. 1990. Relative efficiency of selection methods to improve a ratio of two traits in Tribolium. Theor. Appl. Genet. 80:343-348.

Corl, B. A., L. H. Baumgard, D. A. Dwyer, J. M. Griinari, B. S. Phillips, and D. E. Bauman. 2001. The role of $\Delta^{9}$-desaturase in the production of cis-9, trans-11 CLA. J. Nutr. Biochem. 12:622-630.

Essl, A. 1989. Selection for a ratio of two traits: Results of a simulation study. J. Anim. Breed. Genet. 106:81-88.

Garnsworthy, P. C., S. Feng, A. L. Lock, and M. D. Royal. 2010. Short communication: Heritability of milk fatty acid composition and stearoyl-CoA desaturase indices in dairy cows. J. Dairy Sci. 93:1743-1748.

Griinari, J. M., B. A. Corl, S. H. Lacy, P. Y. Chouinard, K. V. V. Nurmela, and D. E. Bauman. 2000. Conjugated linoleic acid is synthesized endogenously in lactating dairy cows by $\Delta^{9}$-desaturase. J. Nutr. 130:2285-2291.

Gunsett, F. C. 1984. Linear index selection to improve traits defined as ratios. J. Anim. Sci. 59:1185-1193.

Haug, A., A. Høstmark, and O. Harstad. 2007. Bovine milk in human nutrition-A review. Lipids Health Dis. 6:25.

Kay, J. K., T. R. Mackle, M. J. Auldist, N. A. Thomson, and D. E. Bauman. 2004. Endogenous synthesis of cis-9, trans-11 conjugated linoleic acid in dairy cows fed fresh pasture. J. Dairy Sci. $87: 369-378$.

Kelsey, J. A., B. A. Corl, R. J. Collier, and D. E. Bauman. 2003 The effect of breed, parity and stage of lactation on conjugated linoleic acid (CLA) in milk fat from dairy cows. J. Dairy Sci. 86:2588-2597.

Kepler, C. R., and S. B. Tove. 1967. Biohydrogenation of unsaturated fatty acids. J. Biol. Chem. 242:5686-5692.
Mele, M., R. Dal Zotto, M. Cassandro, G. Conte, A. Serra, A. Buccioni, G. Bittante, and P. Secchiari. 2009. Genetic parameters for conjugated linoleic acid, selected milk fatty acids, and milk fatty acid unsaturation of Italian Holstein-Friesian cows. J. Dairy Sci. 92:392-400.

Meyer, K. 2007. WOMBAT-A tool for mixed model analyses in quantitative genetics by restricted maximum likelihood (REML). J. Zhejiang Univ. Sci. B 8:815-821.

Ntambi, J. M., and M. Miyazaki. 2004. Regulation of stearoyl-CoA desaturases and role in metabolism. Prog. Lipid Res. 43:91-104.

Parodi, P. W. 1999. Conjugated linoleic acid and other anticarcinogenic agents of bovine milk fat. J. Dairy Sci. 82:1339-1349.

Royal, M. D., and P. C. Garnsworthy. 2005. Estimation of genetic variation in $\Delta^{9}$-desaturase enzyme activity in dairy cows. Page 52 in Proc. Br. Soc. Anim. Sci., York, UK. Br. Soc. Anim. Sci., Penicuik, Midlothian, Scotland.

Schennink, A., J. M. L. Heck, H. Bovenhuis, M. H. P. W. Visker, H. J. F. van Valenberg, and J. A. M. van Arendonk. 2008. Milk fatty acid unsaturation: Genetic parameters and effects of stearoyl-CoA desaturase (SCD1) and acyl CoA: Diacylglycerol acyltransferase 1 (DGAT1). J. Dairy Sci. 91:2135-2143.

Soyeurt, H., F. Dehareng, P. Mayeres, C. Bertozzi, and N. Gengler. 2008. Variation of $\Delta^{9}$-desaturase activity in dairy cattle. J. Dairy Sci. 91:3211-3224.

Stoop, W. M., J. A. M. van Arendonk, J. M. L. Heck, H. J. F. van Valenberg, and H. Bovenhuis. 2008. Genetic parameters for major milk fatty acids and milk production traits of Dutch HolsteinFriesians. J. Dairy Sci. 91:385-394.

Sun, Q., J. Ma, H. Campos, and F. B. Hu. 2007. Plasma and erythrocyte biomarkers of dairy fat intake and risk of ischemic heart disease. Am. J. Clin. Nutr. 86:929-937. 